\title{
Femtosecond laser micromachining of zirconia green
} bodies

\section{Hyesung Shin and Wonjong Jeong}

Department of Mechanical Engineering,

Pohang University of Science and Technology (POSTECH),

Pohang 790-784, South Korea

Email: faxlucidus@postech.ac.kr

Email: jwj2327@postech.ac.kr

\section{Youngsam Kwon}

\author{
Cetatech, \\ Sacheon 664-953, South Korea \\ Email: yskwon@cetatech.com
}

\section{Dongsik Kim*}

Department of Mechanical Engineering,

Pohang University of Science and Technology (POSTECH),

Pohang 790-784, South Korea

Email: dskim87@postech.ac.kr

*Corresponding author

\begin{abstract}
In this study, we developed micromachining processes using a femtosecond Ti: sapphire laser for zirconia green bodies, i.e., composites comprising zirconia particles and polymer binders. The laser ablation characteristics of the zirconia composites were analysed to optimise the process. In comparison with bulk zirconia, ablation of the zirconia green bodies occurred at lower fluences. In the high-fluence regime, laser irradiation directly ablated the zirconia particles, causing aggregation of resolidified particles. The ablated depth increased with fluence $(F)$ and overlap number $(N)$ initially, but saturated when $F$ and $N$ became larger. Microchannels with a minimum width of $4 \mu \mathrm{m}$ were fabricated. The microchannel width decreased with decreasing fluence and overlap number. Microholes, microchannels and three-dimensional structures with a size of several tens of micrometres and aspect ratio of 5-15 were successfully fabricated using the zirconia composite.
\end{abstract}

Keywords: femtosecond laser; green body; laser micromachining; powder injection moulding; zirconia.

Reference to this paper should be made as follows: Shin, H., Jeong, W., Kwon, Y. and Kim, D. (2017) 'Femtosecond laser micromachining of zirconia green bodies', Int. J. Additive and Subtractive Materials Manufacturing, Vol. 1, No. 1, pp.104-117. 
Biographical notes: Hyesung Shin is a Doctoral student in the Mechanical Engineering Departments at POSTECH (South Korea). He received her Bachelors of Mechanical Engineering in POSTECH, South Korea. His research interests include ultrafast laser micromachining, and thermal analysis of laser material processing.

Wonjong Jeong studied for PhD degree in POSTECH, South Korea. He received his Bachelors of Mechanical Engineering in SEOULTECH, South Korea. His research interests are laser material processing including laser ablation, cleaning, sintering and especially metal $3 \mathrm{D}$ printing.

Youngsam Kwon is the CEO of the Cetatech. He received his Masters of Engineering and $\mathrm{PhD}$ degree from the POSTECH, South Korea, and Bachelors of Engineering from the Hanyang University, South Korea. His research interests include powder metallurgy and powder injection moulding.

Dongsik Kim received his PhD degree from UC Berkeley (USA) in 1998. After serving as an Assistant Professor in the Mechanical Eng. Department at UT Austin (USA) for two years, he joined POSTECH (Suth Korea) in 2000 and is currently the Head Professor at the Mechanical Engineering Department. His main research interests are in laser materials processing and thermal sensing/analysis with emphasis on laser micromachining, laser 3D printing of metal/semiconductor parts, modelling, simulation of high-power laser interaction with materials and microscale thermal sensing. He published numerous archival journal papers and won several awards, including the inaugural Kwangwon Award from KSLP and the Netzsch KSTP Thermophysical Properties Award.

This paper is a revised and expanded version of a paper entitled 'Micromachining of zirconia greenbody using fs laser' presented at Autumn Annual Proceeding of Korean Society of Laser Processing, Gwangju, South Korea, 26-27 November 2015.

\section{Introduction}

Zirconia (zirconium dioxide, $\mathrm{ZrO}_{2}$ ) is an attractive material because of its high strength, corrosion resistance, chemical stability, biocompatibility and high thermal resistance. Recently, microscale parts such as micro electro mechanical components, biosensors and microfluidic components, have been fabricated using zirconia for various purposes (Barsch et al., 2009; Çetinel and Bauer, 2013; Cheah et al., 2012; Denry and Kelly, 2008; Rajabi et al., 2015). Microscale components often have microholes and microchannels as small as several micrometers in size. However, the high strength and hardness of zirconia make it difficult to fabricate micrometer-sized structures on zirconia effectively, especially with conventional machining techniques using contact tools. Problems such as severe tool wear and excessive processing time significantly reduce the productivity of zirconia parts (Lee and Kim, 2009; Li et al., 2012; Romanus et al., 2014).

Micro powder injection moulding ( $\mu$-PIM) using micro injection moulding technology has been developed to overcome the problems of PIM in the production of microscale parts (Attia and Alcock, 2011; Loh et al., 2008; Piotter et al., 2011). In the $\mu$-PIM process, micrometer- or nanometer-sized metal/ceramic powders are mixed with 
polymer binders and injected into a mould of near net shape. The powder is then transformed into a bulk material via a sintering process after removal of the polymer binder through a debinding process. $\mu$-PIM can dramatically increase the productivity of manufacturing with hard-to-process materials. However, the structural shape and feature size of near-net-shape components fabricated by $\mu$-PIM are limited. One of the critical factors that limit the feature size is voids in a product induced by viscous behaviour of powder compounds. Several studies designed to deduce the optimal $\mu$-PIM conditions, including the optimal binder system, feedstock, part geometry, mould design and conditions for filling the mould without forming cavities, have been reported in the literature (Liu et al., 2011; Meng et al., 2010; Yu et al., 2009). Another problem associated with $\mu$-PIM is that a micro structure smaller than the powder size cannot be fabricated. The aforementioned problems of $\mu$-PIM become an obstacle in fabricating microscale components with several micrometer-sized structures. To fabricate a microstructure using a ceramic material, nanoparticles and a micromould with fine features can be used. For example, a nozzle plate with a $7-\mu \mathrm{m}$-wide trench was fabricated using a microstructured nickel mould manufactured by X-ray lithography and electroforming (Müller et al., 2010). The shape of such micromoulds must be carefully designed to avoid the generation of cavities.

Figure 1 Concept of hybrid manufacturing process of laser micromachining and powder injection moulding (see online version for colours)

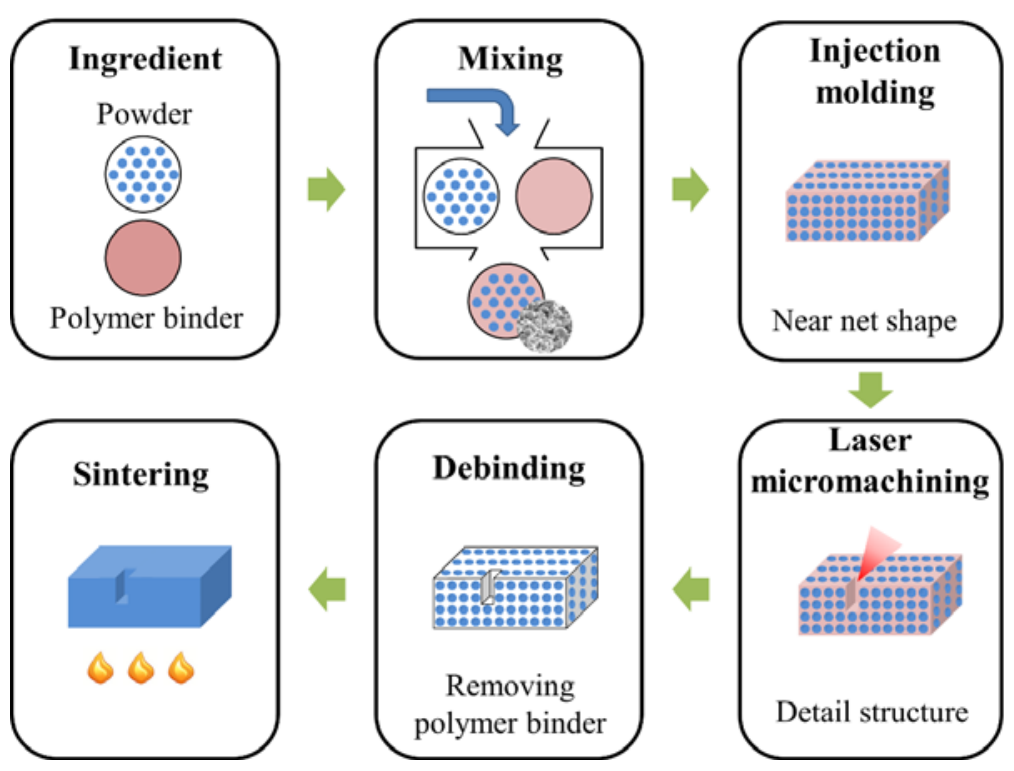

To overcome the limitation of $\mu$-PIM in fabricating complex-shaped products, several hybrid manufacturing processes that combine micromachining and PIM have been developed (Ahn et al., 2014; Besshi et al., 1999; Li et al., 2012; Nowak et al., 2008). In these processes, mechanical machining was typically used to fabricate microstructures on green bodies prior to sintering. However, cracks were easily generated on the surface because of the contact force between the tools and green bodies (Besshi et al., 1999). Therefore, pre-sintering of a green body, i.e., partial sintering was required as an additional step. The pre-sintered green body exhibited reduced surface damage, whereas 
the enhanced strength of the pre-sintered green body increased tool wear during the machining of ceramics (Li et al., 2012). Laser micromachining using a femtosecond laser was used to fabricate microscale structures on a stainless steel green body without damaging the green body (Ahn et al., 2014). Microstructured green bodies were easily fabricated by a laser beam without pre-sintering (Figure 1). In a hybrid process, the laser beam either decomposed the polymer binder to detach the particles or directly ablated the individual particles. Investigations were conducted to develop laser micromachining processes for various lasers and green bodies, i.e., composites of microparticles and polymer binders (Guo et al., 2003a; Imen and Allen, 1999). A Nd: YAG is also effective for drilling in a gelcast alumina composite without spattering or microcrack generation (Guo et al., 2003b). A pulsed CO2 laser was used to drill holes in an alumina-polymer composite (Imen and Allen, 1999). Gas flows generated by decomposition of the polymer binder were observed to be sufficiently strong to detach the ceramic particles from the surface. Imen and Allen (1999) explained that the main removal mechanism of ceramic-polymer composite at low fluence is ablation of the polymer binder material rather than direct ablation. Similar mechanisms have been proposed to explain ablation of metal-polymer composites at low fluence below the ablation threshold of the metal using a Nd: YAG laser (Slocombe and Li, 2000). However, femtosecond laser irradiation can directly ablate the metal particles from a composite material, enhancing the resolution of micromachining (Ahn et al., 2014). Ahn et al. (2014) sharply cut stainless steel particles $8.8 \mu \mathrm{m}$ in diameter using femtosecond laser pulses at a wavelength of $266 \mathrm{~nm}$, without causing significant thermal side effects.

The mechanisms of zirconia green body machining subject to various laser parameters, including wavelength, fluence and pulse width, have not been clearly revealed, especially for compounds of zirconia nanoparticles. In this work, we investigate femtosecond laser micromachining of zirconia green bodies composed of nanometer-sized particles. Analyses are performed using zirconia green bodies before and after debinding, i.e., using two types of zirconia green bodies with or without a polymer binder. As the debinding process removes the polymer binder, the $\mathrm{ZrO}_{2}$ particles form a structure by van der Waals interaction in the green bodies after debinding. The characteristics of laser ablation of bulk zirconia and zirconia green bodies are investigated for a Ti: sapphire femtosecond laser. On the basis of the analysis, micromachining processes are developed for fabricating various microstructures on zirconia green bodies.

\section{Experimental}

A zirconia-polymer composite sample was prepared by PIM. The sample was composed of $47 \%$ zirconia nanoparticles (TOSOH zirconia powder, TZ-3YS-E) and $53 \%$ polymer binder in volumetric ratio. The polymer binder consisted of $50 \%$ wax, $22.5 \%$ polyethylene, $22.5 \%$ polypropylene and $5 \%$ stearic acid. According to the specifications provided by the manufacturer, $50 \%$ of the particles were larger than $65 \mathrm{~nm}$ and their average diameter was $90 \mathrm{~nm}$. Zirconia green bodies without a polymer binder were prepared by thermal debinding of the zirconia-polymer composite sample at $900^{\circ} \mathrm{C}$ for $1 \mathrm{~h}$. 
A Ti: sapphire laser $(\lambda=800 \mathrm{~nm}$, full width at half maximum $(\mathrm{FWHM})=50 \mathrm{fs}) \mathrm{was}$ used in the experiments. The experimental setup included the laser source, beam delivery optics, an air blowing system, a translation stage and a process monitoring system for observing the micromachining site (Figure 2). The laser pulse energy was modulated using a half-wave plate and a polariser. An objective lens was used to focus the Ti: sapphire laser beam on the surface of the green body sample. The calculated spot diameter of the Gaussian beam was $18 \mu \mathrm{m}$. The pulse energy E of the Ti: sapphire laser was varied over the range $2-20 \mu \mathrm{J}(0.77$ to $7.7 \mathrm{~J} / \mathrm{cm} 2)$. The sample position was controlled using a three-dimensional (3D) translation stage with a resolution of $1 \mu \mathrm{m}$. A jet of purified air was blown onto the sample surface from a 0.5 -m-diameter nozzle. The impingement angle was $45^{\circ}$ and the regulator pressure was 1 bar, which produces sufficient hydrodynamic force to remove detached particles from the green body surface. After laser processing, the surfaces were analysed by optical microscopy and high-resolution field-emission scanning electron microscopy (FE-SEM).

Figure 2 Experimental setup for laser micromachining (see online version for colours)

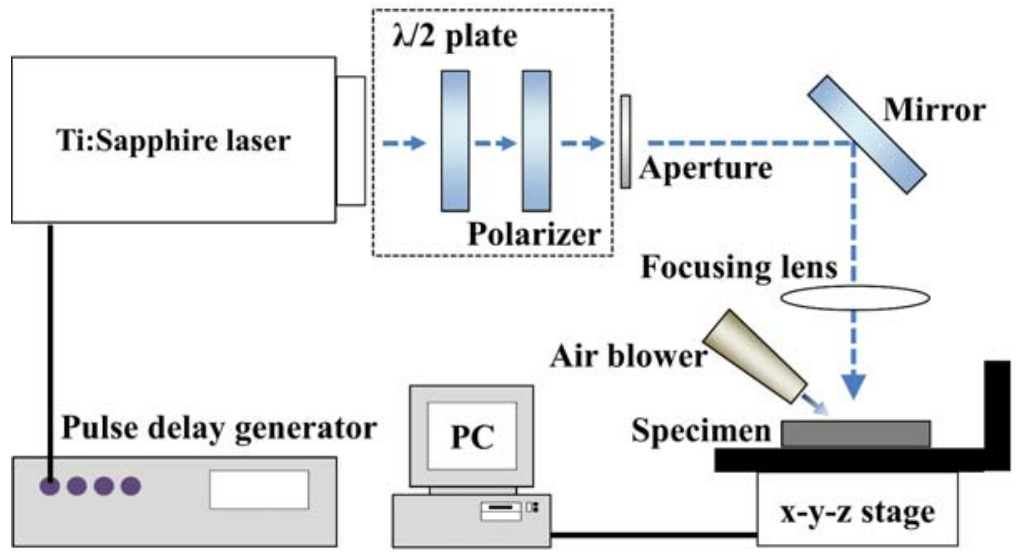

\section{Results and discussion}

To examine the effect of laser fluence $F$ on ablation of zirconia green bodies, circular microholes were drilled using the percussion process with pulse number $N=1,000$ at various fluences from $0.77 \mathrm{~J} / \mathrm{cm}^{2}$ to $7.7 \mathrm{~J} / \mathrm{cm}^{2}$. The ablation threshold fluence $F^{\text {th }}$ was measured for three types zirconia samples; bulk zirconia and green bodies before (with binder) and after debinding (without binder). $F^{\text {th }}$ was determined by analysing the dependency of the crater sizes (squared diameter, $D^{2}$ ) on laser fluence (Figure 3). The following equation indicating logarithmic dependence of ablation rate on laser fluence (Borowiec et al., 2005) was fitted to the experimental data:

$$
D^{2}=2 \omega_{0}^{2} \ln \left(\frac{F}{F^{\text {th }}}\right)
$$

where $\omega_{0}$ is the Gaussian beam radius at the focal plane. 
Figure 3 (a) The dependence of $D^{2}$ on $\ln F$ for evaluation of ablation threshold $F^{\text {th }}$, when $N=1,000$ (b) Ablation diameter as function of fluence

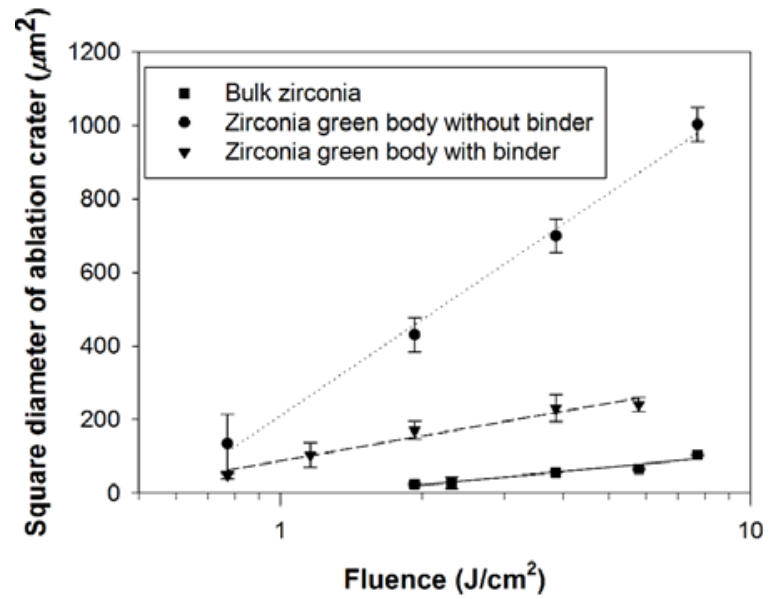

(a)

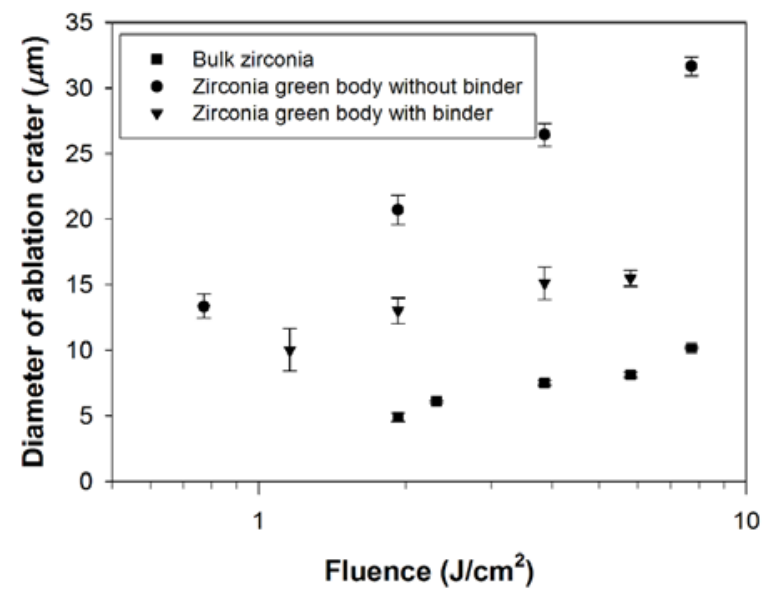

(b)

The measured threshold fluence was $1.09 \mathrm{~J} / \mathrm{cm}^{2}, 0.41 \mathrm{~J} / \mathrm{cm}^{2}$ and $0.51 \mathrm{~J} / \mathrm{cm}^{2}$ for bulk zirconia, the zirconia green body before debinding and the green body after debinding, respectively. The zirconia green body after debinding, which consisted of zirconia nano powder, exhibited an ablation threshold 53\% lower than that of bulk zirconia. Unlike bulk zirconia, removal of zirconia green bodies could be caused by removal of adhesion between the zirconia particles. Thermal expansion and vibration of particles, which are considered the cleaning mechanisms in direct laser removal of particles from surfaces (Lu et al., 1996), are possible explanation for the decrease in ablation threshold of the zirconia green body after debinding. In addition, highly localised heating by near-field effects at the particle-particle interface can break the adhesion between particles. A strong electromagnetic field is formed at contact point between nanoparticles (Ha et al., 2016; Seo et al., 2015). The enhanced field intensity between the two nanoparticles was calculated numerically (COMSOL multiphysics) to be $8.9 \times 1,013 \mathrm{~W} / \mathrm{cm}^{2}$ at incident 
field intensity of $3.6 \times 1,012 \mathrm{~W} / \mathrm{cm}^{2}$. The ablation threshold of the zirconia green body before debinding was $63 \%$ lower than that of bulk zirconia. The reduced ablation threshold of green bodies with a polymer binder has been explained by other authors (Imen and Allen, 1999; Slocombe and Li, 2000). Specifically, the vaporisation of the polymer binder, which has a lower ablation threshold, results in detachment of the particles in green bodies in the low-fluence regime. In the case of ablation of the zirconia green body before debinding, we estimated that decomposition of the polymer binder removed the zirconia particles from the green body in the low-fluence regime. According to crater size [Figure 3(b)], the zirconia green body after debinding exhibited the highest ablation rate among the three samples. Because the debinding process removed the polymer binder that held the particles as a solid composite, particles around the ablation spot were easily detached from the surface (see Figure 4 for comparison between samples before and after debinding). Distortion of the ablation crater in the zirconia green body after debinding increased as fluence increased. Recoil pressure generated by laser ablation and drag force by air jets can induce undesired removal of the particles near the ablation spot. Similar defects of undesired distortion of green bodies have been observed after milling of green body samples (Besshi et al., 1999; Li et al., 2012). The contact force between tools and green bodies generates surface cracks on the green body surfaces, resulting in the detachment of some material from the edge of the green bodies, thereby causing wear of the green bodies. This wear decreases the green body machining accuracy and strength of the machined structures, precluding the fabrication of narrow-wall structures. In addition, particles detached from a zirconia green body after debinding were redeposited around the machined area. Consequently, zirconia green bodies after debinding are not suitable for laser micromachining. Therefore, zirconia green bodies before debinding, i.e., those containing polymer binders, were only used for fabricating micro-3D structures.

Figure 4 Ablation crater of bulk zirconia and zirconia greenbody before and after debinding with $1,000 \mathrm{fs}$ laser pulse at (a) $F=38.6 \mathrm{~J} / \mathrm{cm}^{2}$, (b) $F=19.3 \mathrm{~J} / \mathrm{cm}^{2}, F=3.8 \mathrm{~J} / \mathrm{cm}^{2}$, (c) $F=1.9 \mathrm{~J} / \mathrm{cm}^{2}$ and (d) $F=0.96 \mathrm{~J} / \mathrm{cm}^{2}$

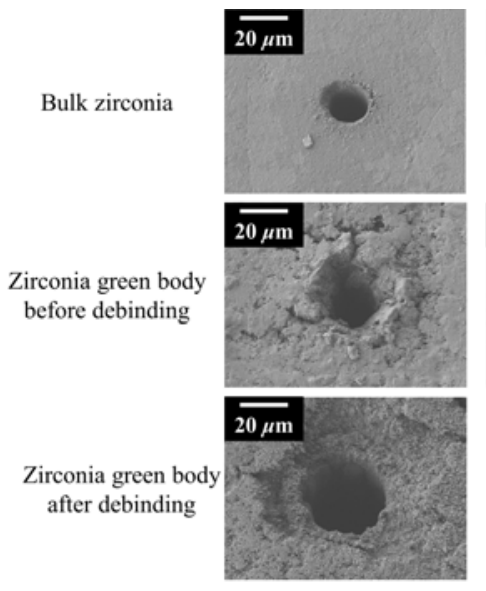

(a)

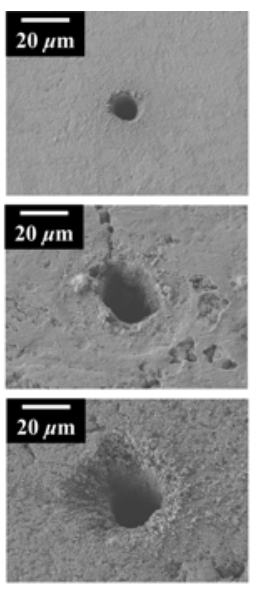

(b)

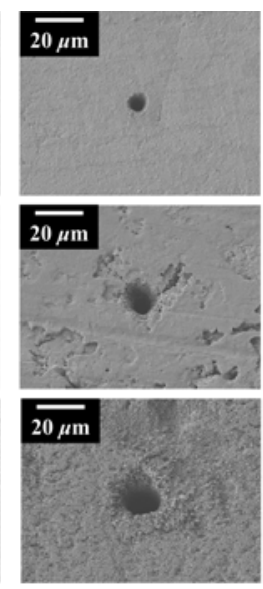

(c)

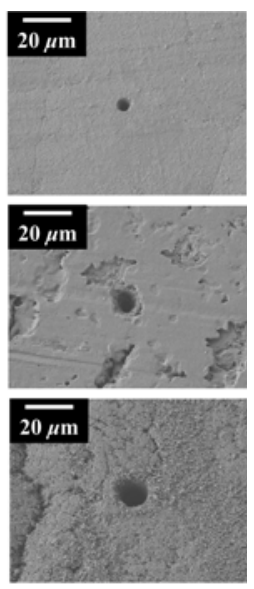

(d) 
The ablation rate was analysed for microchannels instead of microholes. The microholes were too deep to be imaged by atomic force microscopy (AFM). The narrow hole diameter and roughness in the green bodies introduced a substantial reliability problem in measuring the depth of microholes using aoptical 3D profiler. Therefore, the ablation rate was first quantified for microchannels on zirconia green bodies before debinding. Microchannels were fabricated by translating the samples with a speed $S=7 \mu \mathrm{m} / \mathrm{s}$ at various laser fluences. During the process, the number of scans R was varied from 2 to 10 at a frequency of $1 \mathrm{kHz}$, which corresponds to an effective pulse number [defined as overlap number $\mathrm{N}$ in equation (2)] from 2,000 to 10,000 :

$$
N=\frac{D f R}{S}
$$

where $D$ is the ablation diameter, $f$ is the repetition rate, $R$ is the scanning number and $S$ is the scan speed. The ablation diameter $D$ was assumed to be $7 \mu \mathrm{m}$ and the scanning speed $\mathrm{S}$ was $7 \mu \mathrm{m} / \mathrm{s}$. We measured the ablation depth by varying the fluence [Figure 5(a)]. The ablation depth increased almost linearly with $F$ in the fluence range below $\sim 2 \mathrm{~J} / \mathrm{cm}^{2}$ at $N=2,000$ but eventually saturated when $F$ was increased further. The ablated depth initially increased sharply with $N$ at $F=0.77 \mathrm{~J} / \mathrm{cm}^{2}$ and $S=7 \mu \mathrm{m} / \mathrm{s}$, getting saturated when $N>\sim 10^{4}$ [Figure 5(b)]. An aspect ratio as high as 15 with a channel width of $10 \mu \mathrm{m}$ was obtained through adjustment of the process parameters $\left(F=7.7 \mathrm{~J} / \mathrm{cm}^{2}, S=7 \mu \mathrm{m} / \mathrm{s}\right.$ and $R=2$ ). The minimum width of the microchannel was $4 \mu \mathrm{m}$, with an aspect ratio of approximately $7\left(F=0.77 \mathrm{~J} / \mathrm{cm}^{2}, S=7 \mu \mathrm{m} / \mathrm{s}\right.$ and $\left.R=2\right)$. As shown in equation (1), the diameter of the ablated hole was proportional to the spot size and to the logarithm of the fluence. According to the equation, the width of the microchannel could be further reduced by tighter focusing and lower fluence until it reaches the diffraction limit. If the spot size were reduced to $10 \mu \mathrm{m}$ at $F=0.77 \mathrm{~J} / \mathrm{cm}^{2}$ and $S=7 \mu \mathrm{m} / \mathrm{s}$, microchannel width would be $2.2 \mu \mathrm{m}$.

Figure 5 Ablation depth of microchannel as a function of (a) fluence and (b) pulse number under $800 \mathrm{~nm}$ fs laser irradiation at scanning speed of $7 \mu \mathrm{m} / \mathrm{s}$ with air jet blowing

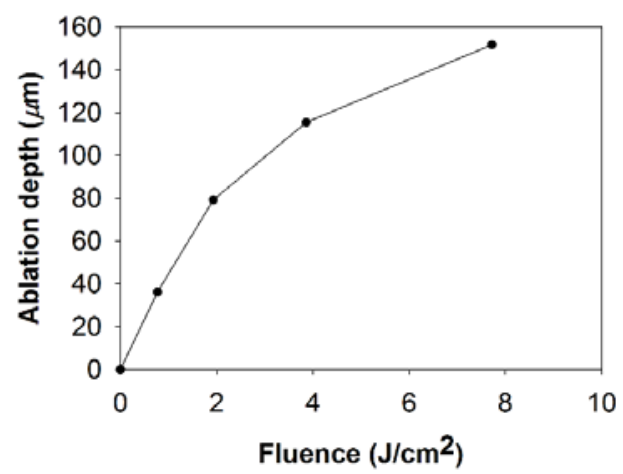

(a)

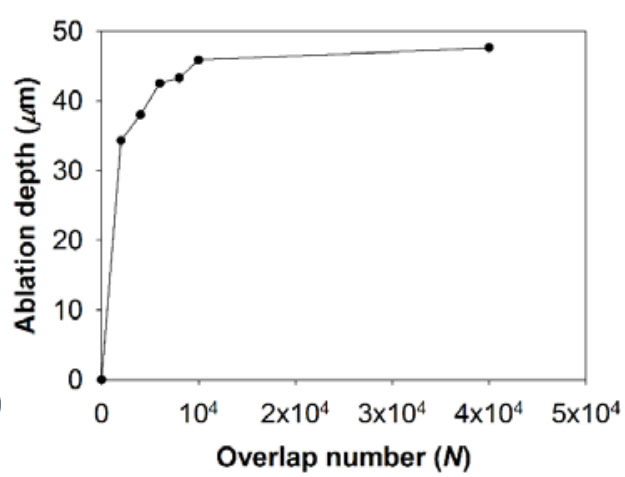

(b)

Microholes, microchannels and other microstructures with different dimensions and depths were fabricated on zirconia green bodies (Figure 6). Circular microholes $7 \mu \mathrm{m}$ 
in diameter were obtained by the percussion drilling method at $N=1,000$ and $F=0.77 \mathrm{~J} / \mathrm{cm}^{2}$ [Figure 6(a)]. The depth of the microholes, as inferred from the depth of microchannels fabricated under the same conditions with a scanning speed $\mathrm{S}=7 \mu \mathrm{m} / \mathrm{s}$, was approximately $35 \mu \mathrm{m}$. An example of a microchannel fabricated at $F=0.77 \mathrm{~J} / \mathrm{cm}^{2}$, $S=7 \mu \mathrm{m} / \mathrm{s}, \mathrm{R}=40$ and $N=40,000$ is shown in Figure $6(\mathrm{~b})$. The width and depth of the microchannel are $8 \mu \mathrm{m}$ and $48 \mu \mathrm{m}$, respectively. Square microholes with different depths were also fabricated by scanning the sample. An example is displayed in Figure 6(c) $\left(S=10 \mu \mathrm{m} / \mathrm{s}\right.$ and $\left.F=0.77 \mathrm{~J} / \mathrm{cm}^{2}\right)$. Fabrication of a relatively complex microstructure is demonstrated in Figure $6(\mathrm{~d})\left(F=0.77 \mathrm{~J} / \mathrm{cm}^{2}\right.$ and $\left.S=10 \mu \mathrm{m} / \mathrm{s}\right)$. The structure composed of 25 - $\mu \mathrm{m}$-thick walls exhibits sharp edges. Figure 6 demonstrates that femtosecond laser micromachining can be used to generate various structures on zirconia green bodies with dimensions as small as a few micrometers.

Figure 6 Machining examples using fs laser pulses, (a) a circular hole of $6 \mu \mathrm{m}$ in diameter (b) a $6 \mu \mathrm{m}$-wide micro channel with an aspect ratio of 6 (c) a $50 \mu \mathrm{m}$-sized square hole (d) a complex structure with a minimum wall widthof $25 \mu \mathrm{m}$

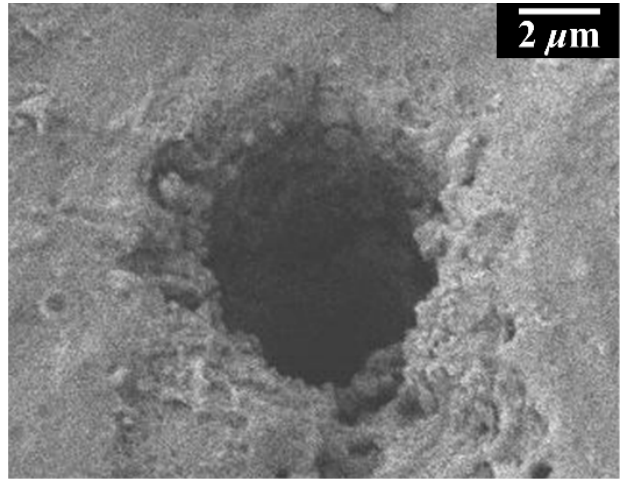

(a)

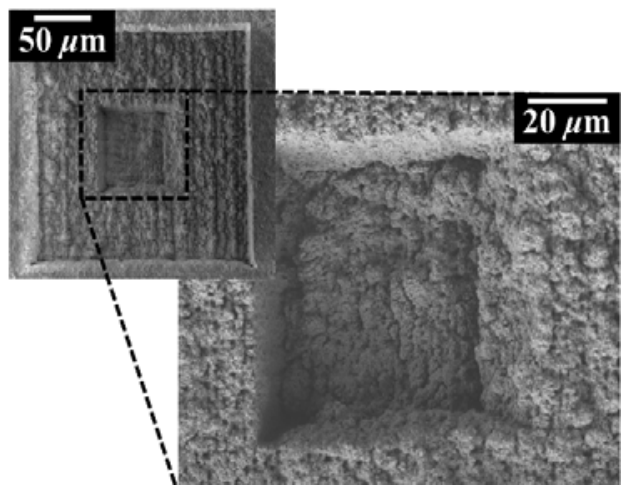

(c)

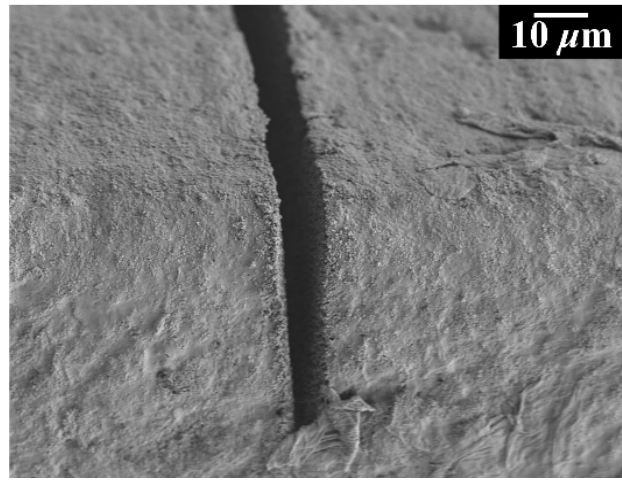

(b)

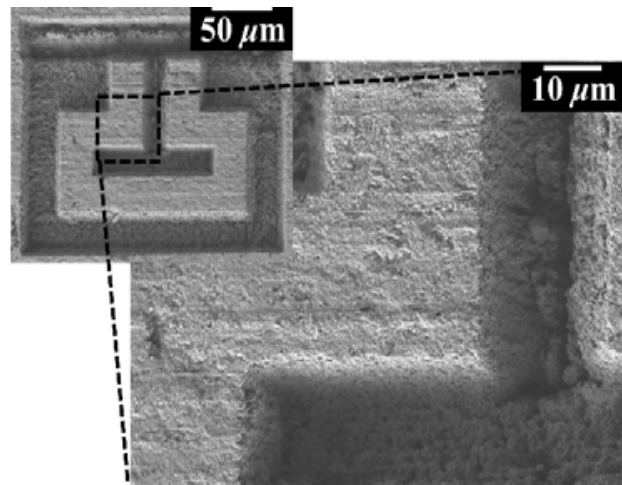

(d)

To confirm that the laser-fabricated microstructures were maintained after the thermal sintering process, we sintered zirconia green bodies micropatterned before and after debinding for $2 \mathrm{~h}$ at $1,400^{\circ} \mathrm{C}$. The sintering process induced shrinkage of the pattern 
(Figure 7). Although the size, i.e., the width and depth, of the sintered structure was decreased to approximately $80 \%$ of the original size, the structures were well preserved.

Figure 7 SEM images showing machined zirconia greenbody, (a) before and (b) after debinding prior to sintering and sintered zirconia $\mu$-PIM sample machined at zirconia green body (c) before and (d) after debinding

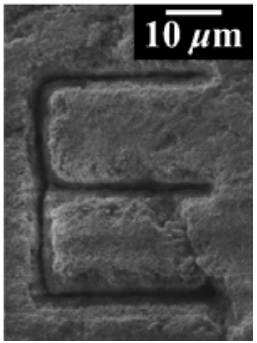

(a)

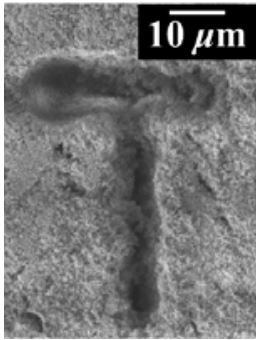

(b)

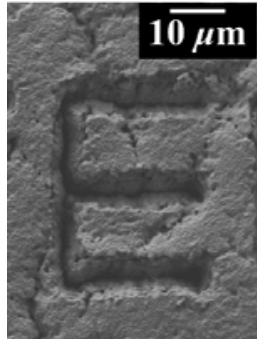

(c)

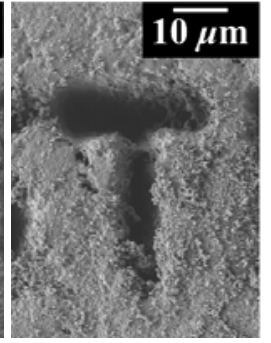

(d)

Figure 8 SEM images showing the cross-section of (a) bare bulk zirconia and bare zirconia greenbody (b) before and (c) after debinding

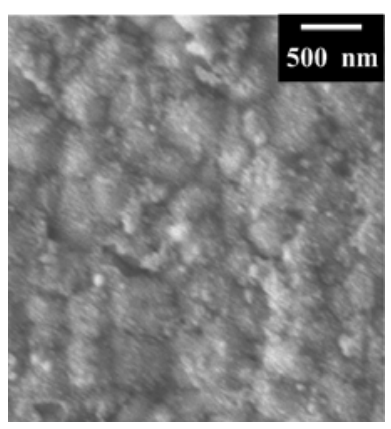

(a)

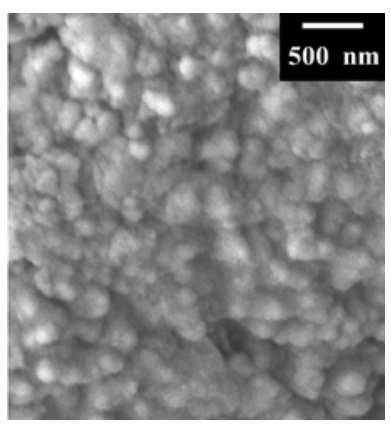

(b)

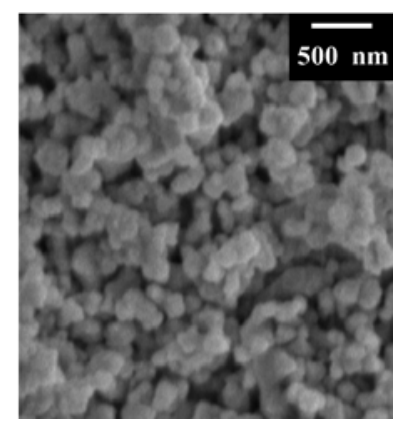

(c)

The surface of the bulk and green bodies of zirconia was inspected by SEM (Figure 8). The original zirconia green body samples before and after debinding, i.e., prior to laser micromachining, are displayed in Figures 8(b) and 8(c), respectively. Although the $90 \mathrm{~nm}$ $\mathrm{ZrO}_{2}$ particles were mixed with the binder in the sample before debinding [Figure 8(b)], the sample after debinding showed the individual particles more clearly [Figure 8(c)]. The top surface around laser-fabricated microholes and the side walls were closely examined by varying the laser fluence $F$ employed in micromachining (Figure 9). The bump formed in the periphery of the hole increased with $\mathrm{F}$, from $\sim 200 \mathrm{~nm}$ at $0.8 \mathrm{~J} / \mathrm{cm}^{2}$ to $\sim 400 \mathrm{~nm}$ at $3.9 \mathrm{~J} / \mathrm{cm}^{2}$. The surface of the ablated spot was covered by aggregated particles larger than $90 \mathrm{~nm}$, with the size of the particles increased with increasing $F$. Because the SEM images in Figure 9 show polymer binder as well as zirconia particles, whether the femtosecond laser pulse melted/ablated the zirconia particles is not clear in these images. However, similar experiments using zirconia green bodies without the binder, i.e., those after debinding, revealed clear melting/resolidification/ablation of zirconia particles (Figure 10). Accordingly, the laser pulse likely induced melting/resolidification/ablation of zirconia particles in the presence 
of the binder. The roughness of the ablated surface increased with $F$ irrespective of the presence or absence of the binder. Figure 10 shows fragmented particles whose diameters range from $\sim 20$ to $\sim 30 \mathrm{~nm}$. Thesenano particles generation can be caused byvarious mechanisms; nucleation of vaporised or melted material (Odachi et al., 2013), and fragmentation by coulomb explosion due to electron ejection from thermionic emission (Grua et al., 2003) or multiphoton ionisation (Kamat et al., 1998).

Figure 9 SEM images showing the behaviours of zirconia greenbody before debinding, corresponding to laser fluences of (a) $0.8 \mathrm{~J} / \mathrm{cm}^{2}$ (b) $1.9 \mathrm{~J} / \mathrm{cm}^{2}$ (c) $2.3 \mathrm{~J} / \mathrm{cm}^{2}$ (d) $3.9 \mathrm{~J} / \mathrm{cm}^{2}$

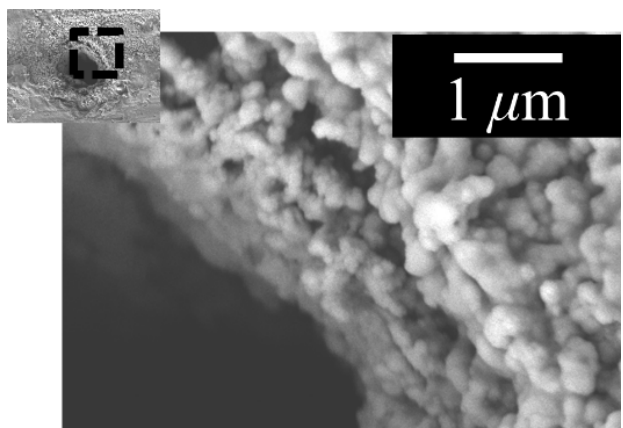

(a)

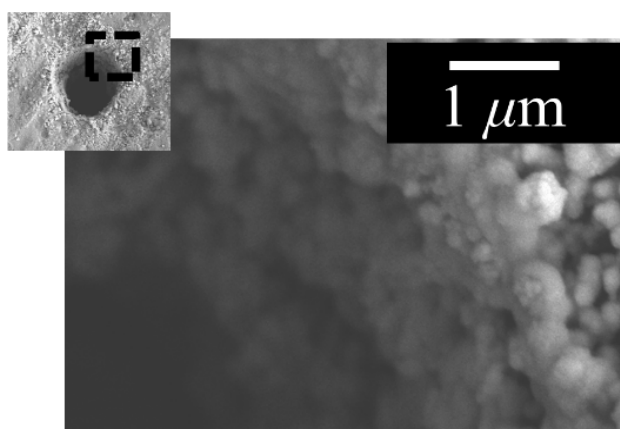

(c)

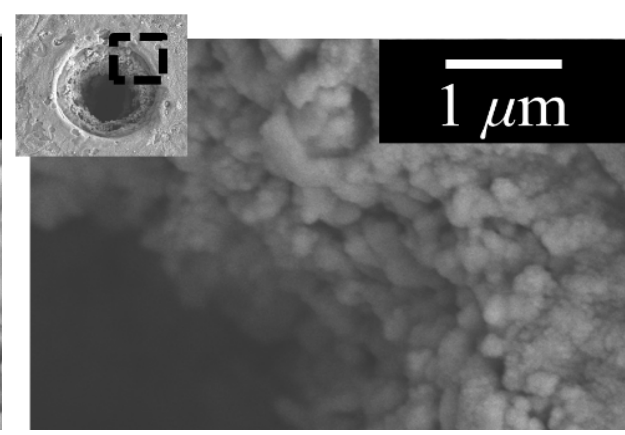

(b)

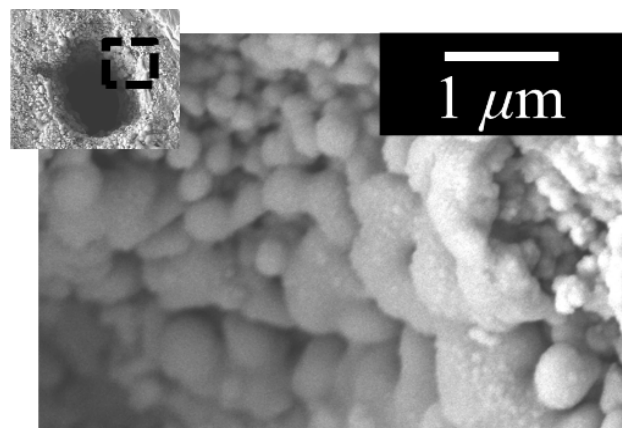

(d)

Figure 10 SEM images showing the behaviours of zirconia greenbody after debinding, corresponding to laser fluences of (a) $0.8 \mathrm{~J} / \mathrm{cm}^{2}$ (b) $1.9 \mathrm{~J} / \mathrm{cm}^{2}$ (c) $2.3 \mathrm{~J} / \mathrm{cm}^{2}$ (d) $3.9 \mathrm{~J} / \mathrm{cm}^{2}$

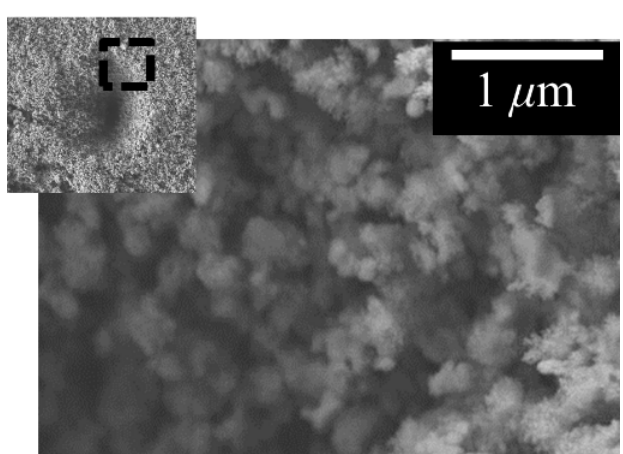

(a)

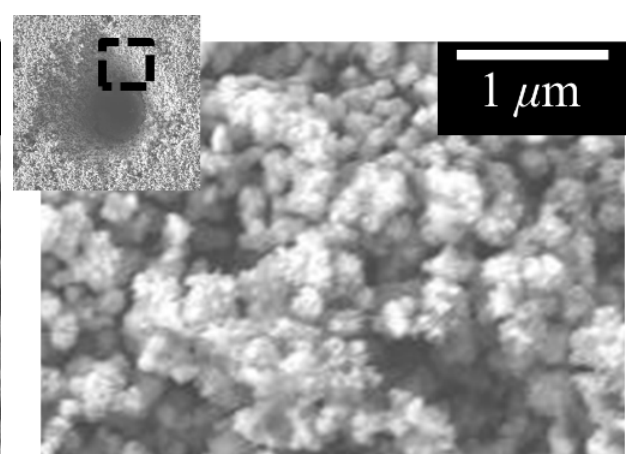

(b) 
Figure 10 SEM images showing the behaviours of zirconia greenbody after debinding, corresponding to laser fluences of (a) $0.8 \mathrm{~J} / \mathrm{cm}^{2}$ (b) $1.9 \mathrm{~J} / \mathrm{cm}^{2}$ (c) $2.3 \mathrm{~J} / \mathrm{cm}^{2}$ (d) $3.9 \mathrm{~J} / \mathrm{cm}^{2}$ (continued)

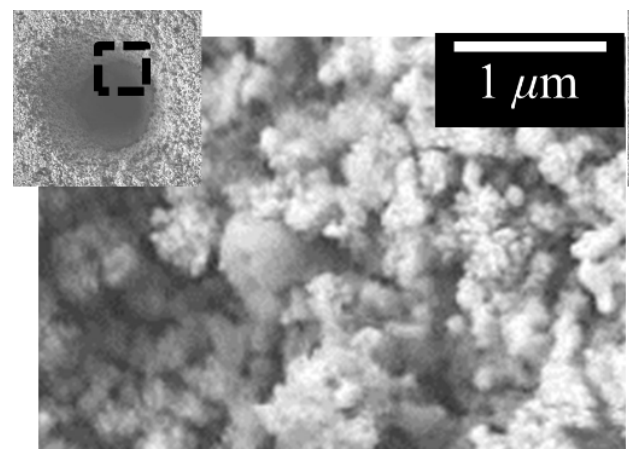

(c)

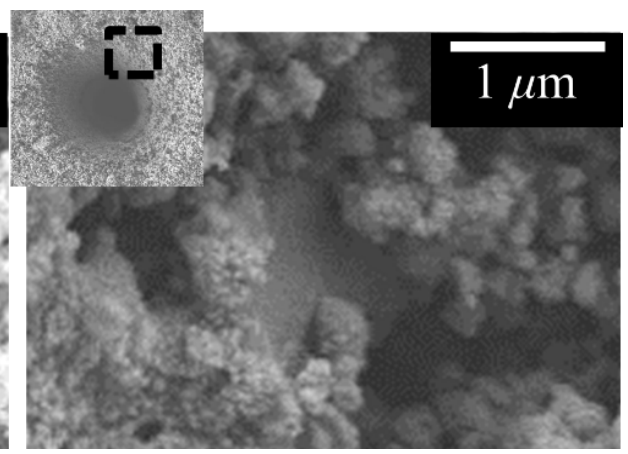

(d)

\section{Conclusions}

In this work, we investigated the micromachining of zirconia green bodies using femtosecond lasers. The ablation mechanism varied depending on laser fluence and the presence of a polymer binder. In the low fluence region, ablation of the polymer binder broke the bonds between zirconia particles and, with the aid of an air jet, removed the detached particles. As fluence increased, femtosecond laser pulses fragmented the zirconia particles and directly removed both the polymer binder and zirconia. Thermal side effects such as aggregation and resolidification of particles were also observed at high fluences. Microchannels with a width of $10 \mu \mathrm{m}$ and a maximum aspect ratio of $\sim 15$ were successfully fabricated at $F=7.7 \mathrm{~J} / \mathrm{cm}^{2}, \mathrm{~S}=7 \mu \mathrm{m} / \mathrm{s}$ and $R=2$. The presented results demonstrate that femtosecond-laser micromachining can be an effective tool for fabricating microholes, microchannels and other more complex structures using zirconia green bodies.

\section{Acknowledgements}

This work was supported by the National Research Foundation of Korea (NRF) grant funded by the Korea government (MSIP) (NO. 2015-0011823, No. 5258-585295).

\section{Reference}

Ahn, D., Seo, C., Park, T., Park, D., Park, S., Kwon, Y. and Kim, D. (2014) 'Micromachining of stainless steel-polymer composites using nanosecond and femtosecond UV lasers', The International Journal of Advanced Manufacturing Technology, Vol. 74, Nos. 9-12, pp.1691-1699

Attia, U.M. and Alcock, J.R. (2011) 'A review of micro-powder injection moulding as a microfabrication technique', Journal of Micromechanics and Microengineering, Vol. 21, No. 4, p.043001. 
Barsch, N., Gatti, A. and Barcikowski, S. (2009) 'Improving laser ablation of zirconia by liquid films: multiple influence of liquids on surface machining and nanoparticle generation', Journal of Laser Micro Nanoengineering, Vol. 4, No. 1, pp.66-70.

Besshi, T., Sato, T. and Tsutsui, I. (1999) 'Machining of alumina green bodies and their dewaxing', Journal of Materials Processing Technology, Vol. 95, Nos. 1-3, pp.133-138.

Borowiec, A., Tiedje, H.F. and Haugen, H.K. (2005) 'Wavelength dependence of the single pulse femtosecond laser ablation threshold of indium phosphide in the 400-2050 nm range', Applied Surface Science, Vol. 243, Nos. 1-4, pp.129-137.

Çetinel, F.A. and Bauer, W. (2013) 'Ceramic micro parts. Part 1: how thermal debinding can be utilized to enhance surface finish and mechanical properties', Journal of the European Ceramic Society, Vol. 33, Nos. 15-16, pp.3123-3134.

Cheah, K.H., Khiew, P.S. and Chin, J.K. (2012) 'Fabrication of a zirconia MEMS-based microthruster by gel casting on PDMS soft molds', Journal of Micromechanics and Microengineering, Vol. 22, No. 9, p.095013.

Denry, I. and Kelly, J.R. (2008) 'State of the art of zirconia for dental applications', Dental Materials, Vol. 24 No. 3, pp.299-307.

Grua, P., Morreeuw, J.P., Bercegol, H., Jonusauskas, G. and Vallée, F. (2003) 'Electron kinetics and emission for metal nanoparticles exposed to intense laser pulses', Physical Review B, Vol. 68, No. 3, p.035424.

Guo, D., Cai, K., Huang, Y. and Li, L. T. (2003a) 'A novel anti-spatter and anti-crack laser drilling technique: application to ceramics', Applied Physics A, Vol. 76, No. 7, pp.1121-1124.

Guo, D., Cai, K., Yang, J.L. and Huang, Y. (2003b) 'Spatter-free laser drilling of alumina ceramics based on gelcasting technology', Journal of the European Ceramic Society, Vol. 23, No. 8, pp.1263-1267.

Ha, J., Lee, B.J., Hwang, D.J. and Kim, D. (2016) 'Femtosecond laser nanowelding of silver nanowires for transparent conductive electrodes', RSC Advances, Vol. 6, No. 89, pp.86232-86239.

Imen, K. and Allen, S.D. (1999) 'Pulse CO2 laser drilling of green alumina ceramic', IEEE Transactions on Advanced Packaging, Vol. 22, No. 4, pp.620-623.

Kamat, P.V., Flumiani, M. and Hartland, G.V. (1998) 'picosecond dynamics of silver nanoclusters. Photoejection of electrons and fragmentation', The Journal of Physical Chemistry B, Vol. 102, No. 17 , pp.3123-3128.

Lee, B.G. and Kim, K.E. (2009) 'Characteristics of micro-hole machining of Al2O3 ceramics by ultrasonic longitudinal vibration', Journal of Ceramic Processing Research, Vol. 10, No. 4, pp.482-490.

Li, J.Z., Wu, T., Yu, Z.Y., Zhang, L., Chen, G.Q. and Guo, D.M. (2012) 'Micro machining of pre-sintered ceramic green body', Journal of Materials Processing Technology, Vol. 212, No. 3, pp.571-579.

Liu, L., Loh, N.H., Tay, B.Y. and Tor, S.B. (2011) 'Microstructure evolution of 316L stainless steel micro components prepared by micro powder injection molding', Powder Technology, Vol. 206, No. 3, pp.246-251.

Loh, N.H., Tor, S.B., Tay, B.Y., Murakoshi, Y. and Maeda, R. (2008) 'Fabrication of micro gear by micro powder injection molding', Microsystem Technologies-Micro-and NanosystemsInformation Storage and Processing Systems, Vol. 14, No. 1, pp.43-50.

Lu, Y.F., Song, W.D., Hong, M.H., Teo, B.S., Chong, T.C. and Low, T.S. (1996) 'Laser removal of particles from magnetic head sliders', Journal of Applied Physics, Vol. 80, No. 1, pp.499-504.

Meng, J.H., Loh, N.H., Fu, G., Tor, S.B. and Tay, B.Y. (2010) 'Replication and characterization of 316L stainless steel micro-mixer by micro powder injection molding', Journal of Alloys and Compounds, Vol. 496, Nos. 1-2, pp.293-299.

Müller, T., Piotter, V., Plewa, K., Guttmann, M., Ritzhaupt-Kleissl, H-J. and Hausselt, J. (2010) 'Ceramic micro parts produced by micro injection molding: latest developments', Microsystem Technologies, Vol. 16, Nos. 8-9, pp.1419-1423. 
Nowak, K.M., Baker, H.J. and Hall, D.R. (2008) 'A model for 'cold' laser ablation of green state ceramic materials', Applied Physics A - Materials Science \& Processing, Vol. 91, No. 2, pp.341-348.

Odachi, G., Sakamoto, R., Hara, K. and Yagi, T. (2013) 'Effect of air on debris formation in femtosecond laser ablation of crystalline Si', Applied Surface Science, Vol. 282, pp.525-530.

Piotter, V., Bauer, W., Knitter, R., Mueller, M., Mueller, T. and Plewa, K. (2011) 'Powder injection moulding of metallic and ceramic micro parts', Microsystem Technologies-Micro-and Nanosystems-Information Storage and Processing Systems, Vol. 17, No. 2, pp.251-263.

Rajabi, J., Zakaria, H., Muhamad, N., Sulong, A. and Fayyaz, A. (2015) 'Fabrication of miniature parts using nano-sized powders and an environmentally friendly binder through micro powder injection molding', Microsystem Technologies, Vol. 21, No. 5, pp.1131-1136.

Romanus, H., Ferraris, E., Bouquet, J., Reynaerts, D. and Lauwers, B. (2014) 'Micromilling of sintered $\mathrm{ZrO}_{2}$ ceramic via cBN and diamond coated tools', Procedia CIRP, Vol. 14, pp.371-376.

Seo, Y., Choi, T-Y., Ha, J., Jeong, D-Y., Lee, S.Y. and Kim, D. (2015) 'Enhancement of stability of aqueous suspension of alumina nanoparticles by femtosecond laser irradiation', Journal of Applied Physics, Vol. 118, No. 11, p.114906.

Slocombe, A. and Li, L. (2000) 'Laser ablation machining of metal/polymer composite materials', Applied Surface Science, Vol. 154-155, pp.617-621.

Yu, P.C., Li, Q.F., Fuh, J.Y.H., Li, T. and Ho, P.W. (2009) 'Micro injection molding of micro gear using nano-sized zirconia powder', Microsystem Technologies-Micro-and NanosystemsInformation Storage and Processing Systems, Vol. 15, No. 3, pp.401-406. 